\title{
KARAKTERISTIK DAN KESEDIAAN CAREGIVERS KELUARGA DARI PASIEN DENGAN PENYAKIT KRONIS TENTANG PEMBENTUKAN SUPPORT GROUP
}

\author{
Sri Rahayu', Teti Rahmawati ${ }^{2}$ \\ ${ }^{1}$ Sekolah Tinggi Ilmu Kesehatan Jayakarta, Yayasan PKP DKI Jakarta \\ ${ }^{2}$ Sekolah Tinggi Ilmu Kesehatan Jayakarta, Yayasan PKP DKI Jakarta \\ E-mail: srirahayu1903@gmail.com
}

\begin{abstract}
Abstrak
Caregivers keluarga memiliki peranan yang sangat penting bagi pasien dengan penyakit kronis. Selama merawat pasien, mereka dapat memiliki berbagai pengalaman, kesuksesan, kegagalan, masalah, dan juga kendala dalam merawat pasien. Tentunya mereka akan merasa stress, cemas, frustasi, depresi, merasa sendiri, dan bahkan kesehatannyapun terganggu. Maka dari itu, perlunya kepedulian dari masyarakat kepada caregivers keluarga dengan mencari solusi seperti ide pembentukan sebuah group. Tujuan dari penelitian ini adalah untuk mengidentifikasi karakteristik dan kesediaan pada caregivers keluarga dari pasien dengan penyakit kronis tentang pembentukan support group. Penelitian kuantitatif dengan desain cross-sectional study digunakan sebagai metode dalam penelitian ini. Sejumlah 97 orang caregivers keluarga dari pasien dengan penyakit kronis terlibat dalam penelitian ini dengan kriteria inklusi dan eklusi. Hasil penelitian

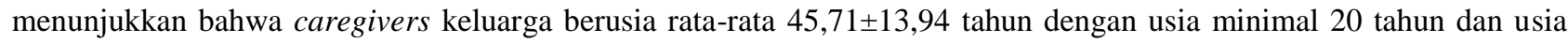
maksimal 83 tahun, 69 orang $(71,1 \%)$ berjenis kelamin perempuan, 46 orang $(47,4 \%)$ memiliki tingkat pendidikan SMA, 58 orang $(59,8 \%)$ bekerja, 41 orang $(42,3 \%)$ memiliki hubungan dengan pasien sebagai istri, dan 69 orang $(71,1 \%)$ bersedia untuk dibentuk support group. Kesimpulan dari penelitian ini adalah diharapkan menjadi landasan dalam pembentukan support group pada populasi caregivers keluarga dari pasien dengan penyakit kronis.
\end{abstract}

Kata Kunci: Caregivers, Keluarga, Support Group

\begin{abstract}
Family caregivers have a crucial role in patients with chronic diseases. During caregiving care, they might have various experiences, successes, failures, problems, and also obstacles in caring the patients. Surely, they might feel stressed, anxious, frustrated, depressed, feel alone, and health problems. Subsequently, they need public attention to by finding solutions such as the idea of creating a group. The purpose of this study was to identify the characteristics and willingness of family caregivers of patients with chronic diseases related to creating support groups. Quantitative research with cross-sectional study design was used. A total of 97 family caregivers of patients with chronic diseases were involved in this study with inclusion and exclusion criteria. The results showed that family caregivers aged an average of $45.71 \pm$ 13.94 years with a minimum age of 20 years and a maximum age of 83 years, 69 people (71.1\%) were female, 46 people (47.4\%) had high school education level, 58 people (59.8\%) was employee, 41 people (42.3\%) have a relationship with patients as housewife, and 69 people (71.1\%) are willing to build a support group. The conclusion of this study is expected to be the foundation in creating a support group in the family caregivers of patients with chronic diseases.
\end{abstract}

Keywords: Family Caregivers, Support Group 


\section{PENDAHULUAN}

Sampai sejauh ini masyarakat Indonesia menganggap bahwasanya yang memberikan perawatan kepada pasien selama 24 jam adalah petugas kesehatan. Padahal hasil penelitian menunjukkan bahwa $90 \%$ perawatan kepada pasien dengan penyakit kronis diberikan oleh caregivers keluarga (Collins \& K Swartz, 2011; Swartz, \& Collins, 2019). Data dari National Alliance for Caregiving \& AARP (2009) menunjukkan bahwa lebih dari $78 \%$ caregivers ialah berasal dari keluarga. Pernyataan ini dikuatkan dengan hasil penelitian di Indonesia yang menyebutkan bahwa mayoritas caregivers yang merawat pasien penyakit kronis adalah keluarga (Rahayu, 2017). Maka dapat disimpulkan bahwa kontribusi caregivers keluarga sangat penting bagi pasien dengan penyakit kronis.

Keberadaan caregivers keluarga sangat dibutuhkan oleh pasien dengan penyakit kronis seperti halnya pasien dengan gagal jantung dan stroke mengingat pasien memerlukan perawatan yang berkelanjutan. Data dari World Health Organization (WHO) (2017) menjelaskan bahwa penyebab utama kematian di dunia adalah karena penyakit kardiovaskuler. Pasien dengan penyakit ini membutuhkan perawatan dalam jangka panjang di rumah (Feinberg, Reinhard, Houser, \& Choula, 2011). Caregivers keluargalah yang mengambil tanggungjawab sepenuhnya untuk merawat pasien (Collins \& K Swartz, 2011). Akan tetapi, sangat disayangkan di Indonesia caregivers belum begitu diperhatikan (Deftia, 2018). Padahal mereka yang sepenuhnya paham betul akan perubahan kondisi kesehatan yang terjadi setiap saat pada pasien.

Caregivers keluarga pada dasarnya adalah orang yang selalu mendampingi dan merawat pasien dengan penyakit kronis. Mereka memiliki peranan yang sangat vital di dalam kehidupan seharihari pasien (Swartz, \& Collins, 2019). Semakin hari, kehadiran mereka semakin dibutuhkan oleh pasien dengan penyakit kronis (Northouse, Williams, Given, McCorkle, \& Netter, 2012; Swartz, \& Collins, 2019). Adapun tugas caregivers selain sebagai keluarga yang membantu pasien dalam aktivitas sehari-hari, mereka juga membantu dalam hal mengingatkan pasien untuk rutin kontrol ke rumah sakit, mengingatkan untuk minum obat secara teratur, mengingatkan untuk mematuhi diet yang harus dijalani, dan sebagainya (Bevans \& Sternberg, 2012; Feinberg et 
al., 2011). Jadi, tugas dan peranan caregivers keluarga sangatlah diperlukan oleh pasien.

Perawatan yang caregivers keluarga lakukan tidak lepas dari berbagai permasalahan. Caregivers keluarga akan dihadapkan pada jumlah jam harus merawat pasien, memikul beban yang tidak ringan, masalah fisik, psikologis, keuangan, juga dapat berefek pada masalah kesehatan pada diri mereka sendiri (Bevans \& Sternberg, 2012; Garlo, O'Leary, Van Ness, \& Fried, 2010; Swartz, \& Collins, 2019). Contohnya ketika caregivers keluarga dihadapkan pada kondisi pasien yang tiba-tiba menurun. Pastinya caregivers keluarga akan tegang, stress, cemas akan kondisi pasien (Bevans \& Sternberg, 2012). Caregivers keluarga dituntut untuk dapat memahami status kesehatan pasien, membantu memprioritaskan perawatan, dan merencanakan perawatan bersama pasien (Gillick, 2014). Selain itu mereka juga dapat mengalami kelelahan merawat pasien dan bahkan depresi (Adelman, Tmanova, Delgado, Dion, \& Lachs, 2014). Maka diperlukan sebuah solusi bagi caregivers keluarga seperti pertemuan yang dihadiri kelompok pendukung (support group).
Hasil penelitian menunjukkan bahwa kelompok pendukung (support group) bermanfaat bagi caregivers keluarga (Chien et al., 2011; Malini, 2015; Noventi \& Khafid, 2018). Di dalam group tersebut, caregivers keluarga dapat berbagi pengalaman, diskusi bersama, dan membuat program mandiri untuk penatalaksanaan penyakit pasien di rumah (Noventi \& Khafid, 2018). Sehingga kesehatan caregivers terjaga dengan adanya solusi diskusi dalam pertemuan support group (Malini, 2015). Pada akhirnya, beban caregivers keluarga berkurang dan kualitas hidupnya meningkat.

Peneliti mengambil kesimpulan dari penjabaran di atas bahwa penelitian ini sangat penting sebagai sumber informasi tentang caregivers keluarga, mencari pemecahan masalah yang di hadapi caregivers keluarga, dan juga untuk meningkatkan kesadaran masyarakat akan pentingnya caregivers keluarga. Maka dari itu, tujuan dari penelitian ini adalah untuk mengidentifikasi karakteristik dan kesediaan caregivers keluarga dari pasien dengan penyakit kronis tentang pembentukan support group.

\section{TINJAUAN TEORI}


Caregivers keluarga merupakan tulang punggung bagi orang dewasa dengan penyakit kronis untuk memberikan sebagian besar perawatan dan dukungan sosial untuk orang yang mereka cintai (Feinberg \& Houser, 2012). Caregivers keluarga yang dimaksud disini adalah anggota keluarga, saudara, pasangan, teman, tetangga yang memiliki hubungan signifikan dengan pasien (National Alliance for Caregiving \& AARP, 2015). Pada penelitian Levine (2011) melaporkan bahwa keluarga merupakan sumber pendukung utama untuk mendampingi dan merawat pasien. Dukungan keluarga dianggap sebagai pendorong utama untuk memberikan perawatan ekstensif, layanan jangka panjang dan dukungan (LTTS) (Feinberg, Reinhard, Houser, \& Choula, 2011, Feinberg \& Houser, 2012).

Caregivers keluarga memiliki beragam tugas yang harus dilakukan untuk pasien. Tugas mereka termasuk menekankan pasien dalam perawatan diri, memantau kepatuhan terapi, membuat janji untuk pemeriksaan medis rutin, membantu dan memantau asupan natrium rendah, membantu dalam perawatan pribadi, mengamati kondisi pasien untuk gejala awal, menangani pasien (Sanford,
Townsend-Rocchicciolli, Horigan, \& Hall, 2011). Tugas mereka dalam memberikan perawatan sangat penting bagi pasien untuk memastikan kehidupan sehari-hari mereka dapat terus berlanjut dengan baik. Untuk membantu meringankan beban caregivers keluarga, mereka perlu adanya fasilitas untuk bertukar fikiran dan cerita kepada orang lain (Deftia, 2018). Salah satunya adalah dengan adanya support group.

Family Caregiver Alliance (FCA) (2019) menjelaskan support group sebagai sebuah komunitas yang dibentuk untuk berdiskusi secara bebas, berinteraksi, belajar dari pengalaman orang lain, dan untuk mendapatkan dukungan dari lingkungan. Caregivers keluarga seperti yang merawat pasien dengan penyakit kronis dapat bertukar fikiran di dalam komunitas mereka masing-masing. American Association of Retired Persons (AARP) (2019) menambahkan bahwa support group juga memberikan tempat yang aman untuk caregivers keluarga menceritakan pengalaman, memberi dan mendapatkan masukan, dan memastikan kebenaran informasi.

\section{METODOLOGI}


Penelitian kuantitatif dengan desain cross sectional study digunakan sebagai metodologi dalam penelitian ini. Tempat penelitian adalah di RSPAD Gatot Soebroto dengan target populasi yaitu caregivers keluarga dari pasien dengan penyakit kronis. Sampel yang terlibat dalam penelitian ini adalah sejumlah 97 orang dengan kriteria inklusi dan eklusi. Adapun kriteria inklusinya adalah usia minimal 17 tahun, caregivers keluarga yang merawat pasien dengan penyakit gagal jantung atau stroke, merupakan caregivers utama, mampu membaca/ memahami Bahasa Indonesia. Sedangkan kriteria eklusinya adalah keluarga yang beda rumah dengan pasien, tidak bersedia menjadi responden. Penelitian ini telah mendapatkan Ethical Clearance dari Komite Etik Fakultas Ilmu Keperawatan Universitas Indonesia dengan No. surat SK-

218/UN2.F12.D1.2.1/ETIK.FIK.2019.

\section{HASIL}

Pada penelitian ini didapatkan beberapa hasil penelitian yang akan dijelaskan secara rinci dalam bentuk tabel dan keterangan sebagai berikut:

Tabel 1. Distribusi Frekuensi Karakteristik Caregivers Keluarga Dari Pasien Dengan Penyakit Kronis (N=97)

\begin{tabular}{llcc}
\hline No & $\begin{array}{l}\text { Karakteristik } \\
\text { Caregivers } \\
\text { Keluarga }\end{array}$ & $\begin{array}{c}\text { Jumlah } \\
(f)\end{array}$ & $\begin{array}{c}\text { Persentase } \\
(\%)\end{array}$ \\
\hline 1 & Jenis Kelamin & & \\
& Laki-laki & 28 & 28.9 \\
& Perempuan & 69 & 71.1 \\
Tingkat & & \\
& Pendidikan & & \\
& Perguruan & 33 & 34,0 \\
Tinggi & & \\
SMA & 46 & 47,4 \\
SMP & 12 & 12,4 \\
SD & 6 & 6,2 \\
Pekerjaan & & \\
Bekerja & 58 & 59,8 \\
Tidak Bekerja & 39 & 40,2 \\
Hubungan & & \\
dengan Pasien & & \\
Suami & 18 & 18,6 \\
Istri & 41 & 42,3 \\
Anak Laki-laki & 12 & 12,4 \\
Anak & 15 & 15,5 \\
Perempuan & & \\
Ayah & 1 & 1,0 \\
Ibu & 3 & 3,1 \\
Kakak & 2 & 2,1 \\
kandung & & \\
Adik kandung & 5 & 5,2 \\
\hline Karakteristik & caregivers & keluarga \\
& &
\end{tabular}

dalam penelitian ini adalah rata-rata berusia 45,71 $\pm 13,94$ dengan usia minimal 20 tahun dan usia maksimal 83 tahun. Pada tabel 1 menunjukkan bahwa sebagian besar perempuan yaitu sejumlah 69 orang $(71,1 \%)$, memiliki tingkat pendidikan SMA sejumlah 46 orang $(47,4 \%)$, bekerja sejumlah 58 orang $(59,8 \%)$, dan hubungan dengan pasien adalah istri sejumlah 41 orang $(42,3 \%)$.

Tabel 2. Disribusi Frekuensi Kesediaan Pembentukan Support Group (N=97) 


\begin{tabular}{llcc}
\hline No & $\begin{array}{l}\text { Kesediaan } \\
\text { Pembentukan } \\
\text { Support } \\
\text { Group }\end{array}$ & $\begin{array}{c}\text { Jumlah } \\
(f)\end{array}$ & $\begin{array}{c}\text { Persentase } \\
(\%)\end{array}$ \\
\hline 1 & Ya & 69 & 71,1 \\
2 & Tidak & 28 & 28,9 \\
\hline & Total & 97 & 100 \\
\hline
\end{tabular}

Pada tabel 2 menunjukkan bahwa dari 97 responden, sebagian besar caregivers keluarga bersedia untuk dibentuknya support group adalah sebanyak 69 orang $(71,1 \%)$.

\section{PEMBAHASAN}

Menurut Data National Alliance for Caregiving \& AARP (2009), karakteristik caregivers keluarga sangat bervariasi yaitu; usia rata-rata 49 tahun, perempuan, kebanyakan adalah keluarga (pasangan, anak laki-laki / anak perempuan, cucu, dan kerabat lainnya), tingkat pendidikan dari sekolah menengah sampai perguruan tinggi (National Alliance for Caregiving \& AARP, 2015). Sedangkan hasil penelitian di Indonesia menyebutkan bahwa karakteristik caregivers keluarga adalah usia rata-rata 48 tahun, sebagian besar perempuan, memiliki tingkat pendidikan SMA, hubungan dengan pasien sebagai istri, dan bekerja (Rahayu, 2017).

Penjelasan tersebut dapat diartikan bahwa usia caregivers keluarga menurut Departemen Kesehatan Republik
Indonesia (2009) termasuk dalam kategori usia lansia awal. Usia ini sejalan dengan usia pasien dimana pasien dengan penyakit kronis berusia pada usia ini juga (Hamzah, 2016). Orang yang merawat pasien mayoritas perempuan karena pasien dengan penyakit kronis terutama pasien gagal jantung penderitanya adalah laki-laki (Hamzah, 2016; Ikawati, 2015). Laki-laki lebih beresiko untuk terkena penyakit kardiovaskuler dibanding dengan perempuan karena secara teori perempuan dilindungi oleh hormone estrogen yang memproteksi tubuhnya. Sehingga hal ini berkaitan dengan jenis kelamin caregivers adalah perempuan dan memiliki hubungan dengan pasien sebagai istri (National Alliance for Caregiving \& AARP, 2004; Rahayu, 2017).). Hal ini juga ditemukan pada penelitian ini bahwa caregivers keluarga adalah sebagian besar istri. Untuk pekerjaan sebagian besar bekerja karena mengingat usia ini masih terhitung usia produktif, dan bekerja demi menafkahi keluarga dan membiayai biaya kesehatan pasangannya.

Pembentukan support group sangat bermanfaat bagi caregivers keluarga. Perlunya pembentukan ini karena caregivers keluarga mendapatkan sedikit perhatian dan sosial support (Hwang et al., 
2011). Akan lebih bijak jika masyarakat mulai peduli terhadap caregivers dengan mulai mengadakan forum diskusi atau kegiatan yang bermanaaf bagi mereka. Pada penelitian yang dilakukan oleh Chien et al. (2011) menjelaskan bahwa dengan adanya support group ternyata memiliki pengaruh yang positif terhadap kesehatan psikologis, beban caregivers, depresi, dan sosial. Lisnawati (2018) menambahkan juga bahwa supportive group dapat menurunkan stres. Secara logika dengan adanya kesempatan bertukar fikiran, berbagi pengalaman dengan orang yang senasip di dalam group dapat mengurangi beban orang tersebut.

Penelitian yang mendukung lainnya adalah yang dilakukan oleh Chu et al. (2011) yang menjelaskan bahwa dengan support group mampu menurunkan kejadian depresi pada caregivers di Taiwan. Di dalam group tersebut, mereka berbagai pengalaman dalam perawatan pasien, kesuksesan bahkan kegagalan dalam merawat di dalam group. Mereka dapat berdiskusi tanpa ada perasaan takut atau diskriminasi. Hal ini juga di pengaruhi oleh budaya di Taiwan yang saling menghargai satu sama lain. Mereka bebas mengemukakan perasaan mereka dengan caregivers lainnya yang memiliki pengalaman yang sama (Chu et al., 2011). Indonesia memiliki beberapa persamaan dengan Taiwan karena sama-sama di Asia. Jadi memungkinkan sekali jika di Indonesia juga terbuka akan diadakannya support group.

Pada dasarnya support group sangat bermanfaat bagi caregivers keluarga dan juga pada pasien khususnya. Pada penelitian ini caregivers keluarga bersedia untuk dibentuknya support group. Ini merefleksikan bahwa caregivers keluarga di Indonesia menyadari akan kebutuhan support group bertemu baik secara langsung maupun secara online. Kegiatan dalam support group dapat berupa edukasi, pelatihan keterampilan, konsultasi, dan dukungan emosi (Chu et al., 2011; Northouse et al., 2012). Jenis kegiatan yang akan diselenggarakan, nantinya akan disesuaikan kembali dengan keinginan caregivers keluarga.

\section{SIMPULAN}

Pada penelitian ini dapat disimpulkan sebagai berikut:

1. Karakteristik caregivers keluarga adalah berusia rata-rata 45,71 tahun, sebagian besar perempuan, berpendidikan SMA, bekerja, 
menikah dan memiliki hubungan sebagai istri.

2. Kesediaan pembentukan support group adalah mayoritas caregivers keluarga bersedia.

\section{SARAN}

Pada penelitian ini diharapkan hasilnya dapat menjembatani peneliti bersama-sama dengan rumah sakit dalam pembentukan support group pada populasi caregivers keluarga dari pasien dengan penyakit kronis. Selain saran, ucapan Terima Kasih Kami haturkan kepada Kementerian Riset, Teknologi, dan Pendidikan Tinggi Republik Indonesia yang telah memberikan Hibah Penelitian Tahun Anggaran 2019. Selain itu juga ucapan terima kasih kepada RSPAD Gatot Soebroto sebagai tempat pengambilan data dan STIKes Jayakarta yang telah memberikan dukungan dalam penelitian ini.

\section{DAFTAR PUSTAKA}

Adelman, R. D., Tmanova, L. L., Delgado, D., Dion, S., \& Lachs, M. S. (2014). Caregiver burden: A clinical review. JAMA - Journal of the American Medical Association, 311(10), 1052-1059. https://doi.org/10.1001/jama.2014.3 04

American Association of Retired Persons (AARP). (2019). How can I find support groups for the caregivers. https://www.aarp.org/caregiving/an swers/info-2017/family-caregiverssupport-groups.html. Diakses pada tanggal 7 Agustus 2019.

Bevans, M., \& Sternberg, E. M. (2012). Caregiving burden, stress, and health effects among family caregivers of adult cancer patients. JAMA - Journal of the American Medical Association, 307(4), 398403.

https://doi.org/10.1001/jama.2012.2 9

Chien, L. Y., Chu, H., Guo, J. L., Liao, Y. M., Chang, L. I., Chen, C. H., \& Chou, K. R. (2011). Caregiver support groups in patients with dementia: A meta-analysis. International Journal of Geriatric Psychiatry, 26(10), 1089-1098. https://doi.org/10.1002/gps.2660

Chu, H., Yang, C. Y., Liao, Y. H., Chang, L. I., Chen, C. H., Lin, C. C., \& Chou, K. R. (2011). The effects of a support group on dementia caregivers' burden and depression. 
Journal of Aging and Health, 23(2), 228-241.

https://doi.org/10.1177/0898264310 381522

Collins, L., \& K Swartz. (2011). Caregiver care. American Family Physician, 1309. Retrieved from https://pdfs.semanticscholar.org/e4 3d/2b346b994f0043e46a2158f356b ac6952466.pdf

Deftia, Sherly (2018). Family caregiver: Sang pengasuh pun butuh diperhatikan.

https://pijarpsikologi.org/familycaregiver-sang-pengasuh-punbutuh-diperhatikan/. Diakses pada tanggal 7 Oktober 2018.

Family Caregiver Alliance (FCA). (2019). Support Groups. https://www.caregiver.org/supportgroups. Diakses pada tanggal 7 Agustus 2019.

Feinberg, L., Reinhard, S. C., Houser, A., \& Choula, R. (2011). Valuing the Invaluable: 2011 Update - The Growing Contributions and Costs of Family Caregiving. AARP Public Policy Institute, 28. Retrieved from http://assets.aarp.org/rgcenter/ppi/lt c/i51-caregiving.pdf

Feinberg, L., \& Houser, A. N. (2012).
Assessing family caregiver needs: Policy and practice considerations. AARP Public Policy Institute. Chicago

Garlo, K., O’Leary, J. R., Van Ness, P. H., \& Fried, T. R. (2010). Burden in caregivers of older adults with advanced illness. Journal of the American Geriatrics Society, 58(12), 2315-2322. https://doi.org/10.1111/j.15325415.2010.03177.x

Gillick, M. (2014). The Critical Role of Caregivers in Achieving. JAMA: The Journal of the American Medical Association, 02215, 11-12. https://doi.org/10.1001/jama.2013.7 310.Conflict

Hamzah, R., \& Widaryati, W. (2017). Hubungan Usia dan Jenis Kelamin dengan Kualitas Hidup pada Penderita Gagal Jantung di RS PKU Muhammadiyah Yogyakarta (Doctoral dissertation, Universitas' Aisyiyah Yogyakarta).

Hwang, B. B., Fleischmann, K. E., Howie-, J., Stotts, N. A., Dracup, K., \& Hour, C. E. (2011). Caregiving for patients with heart failure: impact on patients' families. American Journal of Critical Care, 
$20(6), 431-442$.

Ikawati, Z. (2015). Faktor-Faktor Yang Mempengaruhi Kualitas Hidup Pasien Gagal Jantung Kronik Factors That Influence Quality of Life in Chronic Heart Failure ( Chf ). Jurnal Keperawatan Soedirman (The Soedirman Journal of Nursing), 2015, 259-266.

Levine, C. (2011). The Hospital Nurse's Assessment of Family Caregiver Needs. American Journal of Nursing, 111(10), 47-51. Retrieved from

http://ezproxy.net.ucf.edu/login?url =http://search.ebscohost.com/login. asp $x$ ?direct $=$ true $\& \mathrm{db}=\mathrm{ofm} \& \mathrm{AN}=52$ $5512403 \&$ site $=$ eds-live $\&$ scope $=$ site Lisnawati, S. K., Muhammad, T. A. S., PA, B., Rita, H. W. S. K., Kep, M., \& Kom, S. K. (2018). Pengaruh Supportive Group Therapy terhadap Stres Lansia Dengan Hipertensi di Puskesma Pudakpayung (Doctoral dissertation, Medicine Faculty).

Malini, M. H. (2015). Impact of support group intervention on family system strengths of rural caregivers of stroke patients in India. Australian Journal of Rural Health, 23(2), 95100. https://doi.org/10.1111/ajr.12126

National Alliance for Caregiving, \& AARP. (2004). Caregiving in the U.S., (April), 1-83.

National Alliance for Caregiving, \& AARP. (2009). A Focused Look at Those Caring for Someone Age 50 or Older. Caregiving in the U.S., (November), 1-79.

National Alliance for Caregiving; AARP. Caregiving in the U.S.- AARP 2015 Report. Bethesda, Md: National Alliance for Caregiving; 2015. https://www.aarp.org/content/dam/a arp/ppi/2015/caregiving-in-theunited-states-2015-reportrevised.pdf

Northouse, L., Williams, A. L., Given, B., McCorkle, R., \& Netter, F. H. (2012). Psychosocial care for family caregivers of patients with cancer. Journal of Clinical Oncology, 30(11), 1227-1234. https://doi.org/10.1200/JCO.2011.3 9.5798

Noventi, I., \& Khafid, M. (2018). Self Management Support Program pada penderita Diabetes dengan pendekatan Diabetes Support Group di RSI Surabaya. Universitas Nahdlatul Ulama Surabaya. 
Community Development Journal, 2(1), 1-5.

Pudiarifanti, N., Pramantara, I. D., \& Ikawati, Z. (2015). Faktor-faktor yang Mempengaruhi Kualitas Hidup Pasien Gagal Jantung Kronik. Jurnal Manajemen Dan Pelayanan Farmasi (Journal of Management and Pharmacy Practice), 5(4), 259266.

Rahayu, S. (2017). 印尼心臟衰竭病人之 家屬照顧者的衛教需求. 成功大學 護理學系學位論文 (Educational needs among family caregivers of patients with heart failure in Indonesia). National Cheng Kung University. (Thesis). 1-77.

Sanford, J., Townsend-Rocchicciolli, J., Horigan, A., \& Hall, P. (2011). A Process of Decision Making by Caregivers of Family Members With Heart Failure. Research and Theory for Nursing Practice, 25(1), 55-70.

https://doi.org/10.1891/0889-

7182.25 .1 .55

Swartz, K., \& Collins, L. G. (2019). Caregiver Care. American family physician, 99(11).

WHO. (2009). Kemenkes RI. http://www.depkes.go.id/download. php?file=download/pusdatin/buleti n/buletin-lansia.pdf. Diakses pada tanggal 7 Agustus 2019.

WHO. (2017). Cardiovascular diseases. https://www.who.int/news-room/factsheets/detail/cardiovascular-diseases(cvds). Diakses pada tanggal 2 Mei 2019. 